\title{
Stroke- on- Awakening: Safety of CT- CTA Based Selection for Reperfusion Therapy
}

\author{
Simerpreet Bal, Rohit Bhatia, Nandavar Shobha, Bijoy K. Menon, Sung Il Sohn, \\ Mayank Goyal, Andrew M. Demchuk, Michael D. Hill, for the Calgary CTA \\ group
}

\begin{abstract}
Background: We studied the safety of use of acute reperfusion therapies in patients with stroke- on- awakening using a computed tomographic angiography (CTA) based large vessel occlusion-good scan paradigm in clinical routine. Methods: The CTA database of the Calgary stroke program was reviewed for the period January 2003-March 2010. Patients with stroke-on-awakening with large artery occlusions on CTA, who received conservative, IV thrombolytic and/or endovascular treatment at discretion of the attending stroke neurologist were analyzed. Time of onset was defined by the time last seen or known to be normal. Baseline non-contrast CT scan (NCCT) Alberta Stroke Program Early CT Score (ASPECTS) $>7$ was considered a good scan. Hemorrhage was defined on follow-up brain imaging using ECASS 3 criteria. Independence $(\mathrm{mRS} \leq 2)$ at three months was considered a good clinical outcome. Standard descriptive statistics and multivariable analysis were done. Results: Among 532 patients with large artery occlusions, 70 patients with stroke-on-awakening (13.1\%) were identified. The median age was 69.5 (IQR 24) and 41 (58.6\%) were female; $41(58.6 \%)$ received anti-platelets only and $29(41.4 \%)$ received thrombolytic treatment [IV-12 (17.1\%), IV/IA-12 (17.1\%) and IA-5(7.1\%)]. Unadjusted analysis showed that baseline NCCT ASPECTS $\leq 7(\mathrm{p}=0.002)$ and higher NIHSS scores $(\mathrm{p}=0.018)$ were associated with worse outcomes. There were no PH2 hemorrhages in the IV thrombolytic or endovascular treated group. Functional outcome was not different by treatment. Conclusion: When carefully selected using CT -CTA, by a good scan (ASPECTS > 7) occlusion paradigm, acute reperfusion therapies in patients with stroke-on-awakening can be performed safely in clinical routine.
\end{abstract}

RÉSUMÉ: Accident vasculaire cérébral constaté au réveil : sécurité de la sélection des patients par CT-CTA pour le traitement de reperfusion. Contexte : Nous avons étudié la sécurité de l'utilisation des thérapies de reperfusion en phase aiguë, chez les patients présentant un accident vasculaire cérébral (AVC) au réveil, au moyen de l'angiographie par tomodensitométrie (AT) basée sur le paradigme du scan démontrant la présence d'occlusion de gros vaisseaux en pratique clinique. Méthodes : La période de janvier 2003 à mars 2010 de la base de données AT du programme d'AVC de Calgary a été revue. Les dossiers des patients présentant un AVC au réveil, qui avaient des occlusions de grosses artères à l'AT et qui ont reçu un traitement conservateur, un traitement thrombolytique IV et/ou un traitement endovasculaire à la discrétion du neurologue traitant, ont été analysés. Le moment de l'apparition de l'AVC était défini comme le moment où le patient avait été vu ou était connu comme ayant été normal pour la dernière fois. Un score $>7$ au CT scan sans contraste (CTSC) selon l'échelle Alberta Stroke Program Early CT Score (ASPECTS) était considéré comme un bon scan. L'hémorragie était identifiée à l'imagerie du cerveau effectuée au cours du suivi au moyen des critères ECASS3. L'autonomie (mRS $\leq 2$ ) 3 mois après l'événement était considérée comme une bonne issue clinique. Nous avons utilisé des méthodes standards de statistique descriptive ainsi que l'analyse multivariée. Résultats : Parmi les 532 patients qui présentaient une occlusion d'une grosse artère, nous avons identifié 70 patients ayant présenté un AVC au réveil $(13,1 \%)$. L'âge médian des patients était 69,5 ans (écart interquartile 24) et $41(58,6 \%)$ étaient des femmes ; $41(58,6 \%)$ ont reçu seulement un anti-plaquettaire et $29(41,4 \%)$ ont reçu un traitement thrombolytique [IV-12 (17,1\%), IV/IA-12 (17,1\%) et IA-5 (7,1\%)]. L'analyse sans ajustement des données a montré qu'un score ASPECTS au CTSC $\leq 7(\mathrm{p}=00,2)$ et des scores plus élevés au NIHSS p $=0,018)$ étaient associés à une issue moins favorable. Il n'y a eu aucune hémorragie parenchymateuse de type PH2 chez les patients ayant reçu un traitement thrombolytique IV ou dans le groupe ayant subi un traitement endovasculaire. L'issue fonctionnelle n'était pas différente selon le traitement reçu. Conclusion : En pratique clinique, quand les patients sont bien choisis au moyen du CT-CTA (score ASPECTS >7), les thérapies de reperfusion chez les patients présentant un AVC au réveil peuvent être administrées de façon sécuritaire en phase aiguë de l'AVC.

Can J Neurol Sci. 2014; 41: 182-186

From the Section of Neurology (SB), Faculty of Medicine, Health Sciences Centre, University of Manitoba, Winnipeg, Manitoba; Calgary Stroke Program, Department of Clinical Neuroscienes (BM, AMD, MDH), Department of Radiology (MG, AMD, MDH), Hotchkiss Brain Institute, Faculty of Medicine, University of Calgary, Calgary, Alberta, Canada; All India Institute of Medical Sciences (RB), New Delhi; Bangalore Neuro Centre, (NS), Vagus Superspecialty Hospital, Bhagwan Mahaveer Jain Hospital, Vikram Hospital, Bangalore, India; Department of Neurology (SIS), Dongsan Medical Centre, Keimyung University School of Medicine, Daegu, South Korea.

Received July 15, 2013. Final Revisions Submitted September 16, 2013.

Correspondence to: Michael D. Hill, Calgary Stroke Program, Department of Clinical Neurosciences, Hotchkiss Brain Institute, University of Calgary, Foothills Hospital, Rm 1242A, 140329 th Street NW, Calgary, Alberta, T2N 2T9, Canada. Email: michael.hill@ucalgary.ca. 
Approximately, 10-27\% of all acute ischemic strokes (AIS) occur during sleep, with the patients or relatives becoming aware of their neurological deficits on awakening. ${ }^{1-4}$ No consensus exists on acute treatment of stroke-on-awakening. Because stroke onset is timed from the time last seen well, typically the evening prior, most patients with stroke-on-awakening therefore fall outside a standard 4.5 hour (hr) time window, precluding thrombolysis.

A surrogate measure of time from stroke onset may be defined using imaging as a biomarker. The idea that there is a tissue-window of salvageable brain among stroke-on-awakening patients is a corollary of the diffusion-perfusion mismatch hypothesis. There is only one computed tomography (CT) based trial (AbESTT-2 Trial) to date, which examined the effect of treatment with abciximab on outcomes among patients with stroke-on-awakening; the trial had to be terminated prematurely due to an increased incidence of intracranial hemorrhage in the treatment arm. ${ }^{5}$ Planned clinical trials will examine the issue of use of thrombolytic therapy in patients with stroke on awakening: (WAKE-UP - NCT01525290 and EXTEND NCT01580839).

It is known that there is an increased risk of symptomatic intracranial hemorrhage ( $\mathrm{ICH})$ secondary to thrombolysis as time from onset elapses. ${ }^{6,7}$ Because no definitive trials have been completed in this patient population there is a complete lack of data on efficacy; tests of efficacy are predicated on demonstrated safety. Thus, currently the primary concern with treating strokeon-awakening patients is safety defined by the risk of hemorrhage. Patients with a small core of established infarction have the lowest risk of hemorrhage. ${ }^{8}$ Others have used multimodal MR imaging or CT perfusion imaging to define candidates for thrombolysis outside of proven treatment windows. ${ }^{9}$ We believe that a simpler CT-based paradigm may be used to treat selected patients. We previously conducted a formal pilot study of the use of non-contrast CT and CT angiography (CTA) to define a thrombolysis population in patients with stroke-on-awakening. In that study, we have used a 'good-scanocclusion' model for selecting such patients, defined by CT and CT angiography (NCCT ASPECTS $>7$ and evidence of occlusion on CTA). ${ }^{10}$ We report our experience in clinical routine on the safety of acute treatment in patients with stroke-onawakening and the factors predicting outcomes for conservative, IV thrombolytic and endovascular treatment among patients with stroke-on-awakening.

\section{Methods}

The CT angiography (CTA) database of the Calgary stroke program, which is approved for research use by the conjoint human research ethics board at university of Calgary, was reviewed for the period Jan03-Mar10. The CTA database includes information on patients who came to Emergency department at Foothills Medical Center with symptoms of stroke/minor stroke/transient ischemic attack (TIA). Patients with stroke-on-awakening with proximal vessel large artery occlusions in anterior and posterior circulations and who were treated in clinical routine (not within a cohort study or randomized controlled trial (RCT)) were analyzed. Patients with suspected small vessel ischemic disease or no occlusion on baseline CTA were excluded. The time of onset was defined when the patient was last seen or known to be normal. Baseline demographic and clinical data were collected for all patients. Stroke-on-awakening was defined as stroke-related deficits that were noticed first on awakening. Patients were treated at the discretion of the attending neurologist of the day. Patients who received IV thrombolysis ( $0.9 \mathrm{mg} / \mathrm{kg}$ tPA) and/or endovascular treatment (MERCI retriever, PENUMBRA stroke system) were treated according to the good-scan-occlusion paradigm as judged by the attending stroke neurologist. The off label nature and additional risk was explained to the patient's relatives or legally authorized decision maker. Patients not thrombolysed were treated conservatively with antiplatelet therapy and stroke unit care. Blood pressure was managed according to the Canadian Best-Practice Guidelines. ${ }^{11}$

Standard non-helical NCCT was performed on a multi-slice scanner (GE Medical Systems, Fairfield, CT, USA or Siemens Medical Solutions, Erlangen, Germany) using 120 kV, 170 mAs with 5-mm slice thickness. Non-contrast CT was followed immediately by CTA with a helical scan technique from arch to vertex. Follow-up imaging was performed on all patients within 24 hours from the first CT scan (for those patients who were treated with thrombolytic therapy) to a maximum of seven days after the initial CT scans. The CT scans were reviewed independently by three reviewers to achieve a consensus score. ${ }^{12}$ ASPECTS was used to score early ischemic change in patients with anterior circulation stroke. ${ }^{13}$ NCCT scans with ASPECTS $>7$ were labeled as good scans. Hemorrhage was defined on follow-up brain imaging using ECASS 3 criteria. ${ }^{14}$ Among those who were treated with endovascular therapy, cerebral angiogram was used to document recanalization. Where possible, the remaining thrombolysed patients were investigated with MRA within 48 hours to determine recanalization.

The primary outcome was safety, defined as symptomatic ICH according to the ECASS-3 definition. ${ }^{14}$ Secondary outcome was a modified Rankin's score (mRS) less than or equal to 2 at three months. Standard descriptive statistics are used to report the data. We used conventional levels of significance at alpha of 0.05 and all tests were two-tailed. To explore predictors of our secondary outcome, a multivariable generalized linear model with log link and binomial distribution was developed to assess predictors of outcome. Only main effects were assessed in the multivariable model.

\section{RESUlTS}

Among 532 patients with large artery occlusions, 70 patients (41 female) with stroke-on-awakening (13.1\%) were identified. The median age was 69.5 (IQR 24); mean time from last seen normal to admission was 542 minutes (min) (SD $212 \mathrm{~min}$ ). Forty-one patients $(59 \%)$ received conservative treatment with anti-platelets only, $29(41 \%)$ received thrombolytic treatment [IV-12 (17\%), IV/IA-12 (17\%) and IA-5 (7\%)]. (Table 1) The mean time from last seen normal to thrombolytic treatments was $516 \mathrm{~min}(\mathrm{SD} \pm 160.2)$ ). Stroke severity was similar between thrombolysed and non-thrombolysed subjects. Baseline ASPECT score was interpreted in real time as favorable in all thrombolysed subjects but on retrospective central review was less than or equal to 7 in half the subjects. Baseline ASPECTS score was lower in the non-thrombolysed cohort. Asymptomatic ICH was observed in 3/41 (7\%) patients in the conservatively 
Table 1: Comparison of baseline characteristics of patients with large artery occlusions presenting with strokeon-awakening with those with known time of onset

\begin{tabular}{|c|c|c|c|c|}
\hline & $\begin{array}{l}\text { Occlusions- Non stroke on } \\
\text { wakening }(n=462)\end{array}$ & $\begin{array}{l}\text { Conservative treatment } \\
(\mathrm{n}=41)\end{array}$ & Thrombolysis $(\mathrm{n}=29)$ & $\mathbf{P}$ \\
\hline Age (median, IQR) & $67(31)$ & $74(21)$ & $68(23)$ & 0.33 \\
\hline Sex - Female & $52 \%$ & $59 \%$ & $59 \%$ & 1.00 \\
\hline Hypertension & $61 \%$ & $66 \%$ & $62 \%$ & 0.80 \\
\hline Diabetes mellitus & $22 \%$ & $17 \%$ & $10 \%$ & 0.50 \\
\hline Atrial fibrillation & $31 \%$ & $44 \%$ & $34 \%$ & 0.29 \\
\hline High cholesterol & $30 \%$ & $15 \%$ & $31 \%$ & 0.14 \\
\hline Anti-platelet treatment & $48 \%$ & $49 \%$ & $59 \%$ & 0.47 \\
\hline Current smoker & $39 \%$ & $46 \%$ & $45 \%$ & 1.00 \\
\hline Baseline NIHSS & $11(9)$ & $13(11)$ & $14(11)$ & 1.00 \\
\hline Baseline ASPECTS & $7(3.5)$ & $6(3.5)$ & $7(3.5)$ & 1.00 \\
\hline Baseline ASPECTS > 7 & $48 \%$ & $29 \%$ & $78 \%$ & 0.26 \\
\hline Onset-to-admission time (SD) & $148(92) \min$ & $540(140) \mathrm{min}$ & $526(112) \mathrm{min}$ & 1.00 \\
\hline Onset-to-IV tPA (n=15) & --- & --- & $516(160) \mathrm{min}$ & \\
\hline Recanalization $\quad[\mathrm{IV}+\mathbf{I A} / \mathbf{I A}]$ & --- & --- & $11 / 17(65 \%)$ & \\
\hline$[\mathbf{I V}]$ & & & $3 / 7(43 \%)$ & \\
\hline HMCAS & $41 \%$ & $32 \%$ & $45 \%$ & 0.31 \\
\hline \multicolumn{5}{|l|}{ Site of occlusion } \\
\hline & M1-MCA & & $49 \%$ & $28 \%$ \\
\hline M2-MCA & & $27 \%$ & $17 \%$ & \\
\hline M1-MCA + ICA & & $12 \%$ & $17 \%$ & \\
\hline M2-MCA + ICA & & $5 \%$ & $7 \%$ & \\
\hline M3-MCA & & $2 \%$ & $0 \%$ & \\
\hline ACA & & $2 \%$ & $0 \%$ & \\
\hline BA & & $2 \%$ & $31 \%$ & \\
\hline
\end{tabular}

IQR = interquartile range; ASPECTS = Alberta Stroke Program Early CT score; IV = intravenous; tPA = tissue plasminogen activator; HMCAS = hyper dense middle cerebral artery sign; $\mathrm{MCA}=$ middle cerebral artery; $\mathrm{ACA}=$ anterior cerebral artery; $\mathrm{BA}=$ basilar artery

treated group and 3 patients $(10 \%)$ in the thrombolytic group [1(IV thrombolysis), 1(IV+IA), 1(IA)]. One patient (2.4\%) had a symptomatic hemorrhage $(\mathrm{PH} 2)$ in the conservative treatment group. Good outcomes occurred in 14/29 (48\%) patients treated with thrombolytic therapy as compared to $17 / 41(42 \%)$ treated conservatively $(\mathrm{p}=0.806)$. Unadjusted analysis showed that baseline NCCT ASPECTS $<=7(\mathrm{p}=0.002)$ and higher national Institutes of Health Stroke Scale (NIHSS) scores $(\mathrm{p}=0.018)$ were associated with worse outcomes. Thrombolysis did not predict independent outcome. (Table 2) In a multivariable model, baseline NCCT ASPECTS $>7$ (RR $2.9 \mathrm{CI}_{95}$ 1.6-5.1), prior antiplatelet medication use (RR $1.7 \mathrm{CI}_{95}$ 1.1-2.9) and age (RR 0.99 per year, $\mathrm{CI}_{95}$ 0.97-0.998) were predictors of good outcome.

\section{Discussion}

Our study highlights the safety of a CT-based paradigm for thrombolytic treatment in clinical routine among patients with stroke-on-awakening and confirms the findings of our previous pilot study. ${ }^{10}$ The low hemorrhage rate is likely due to patient selection and is concordant with a MR based study in patients with stroke on awakening treated with thrombolytic therapy using a DWI-FLAIR volume difference paradigm. ${ }^{15,16}$

Despite the absence of treatment guidelines in this sub-group of patients, there does exist a common and growing understanding that a substantial number stroke-on-awakening patients may have salvageable brain tissue, enough to warrant reperfusion therapies. ${ }^{17-19}$ All the major tPA trials have used NCCT as the primary imaging modality to select patients for 
Table 2: Comparison of complications and outcomes of patients with Strokeon-awakening treated conservatively and with thrombolytic therapy.

\begin{tabular}{l|l|l|l}
\hline & $\begin{array}{l}\text { Conservative } \\
\text { treatment (n=41) }\end{array}$ & $\begin{array}{l}\text { Thrombolysis } \\
(\mathbf{n = 2 9 )}\end{array}$ & $\mathbf{P}$ \\
\hline PH1 & $2 \%$ & $0 \%$ & 1.00 \\
\hline PH2 & $2 \%$ & $0 \%$ & \\
\hline HI1 & $7 \%$ & $0 \%$ & \\
\hline mI2 & $2 \%$ & $3 \%$ & \\
\hline 24h NIHSS & $3(1.5)$ & $3(2)$ & 0.27 \\
\hline mRS 0-2 & $10.5(15.5)$ & $10(13)$ & 0.65 \\
\hline mRS 0-1 & $41 \%$ & $48 \%$ & 0.80 \\
\hline Death & $24 \%$ & $24 \%$ & 1.00 \\
\hline FU ASPECTS & $7 \%$ & $24 \%$ & 0.08 \\
\hline $\begin{array}{l}\text { Outcomes (excluding Basilar } \\
\text { occlusions) }\end{array}$ & $6(3)$ & $6(2.5)$ & 0.79 \\
\hline mRS 0-2 & $12(60 \%)$ & & 0.27 \\
\hline Death & $2(10 \%)$ & $9(45 \%)$ & \\
\hline
\end{tabular}

$\mathrm{PH}=$ parenchymal hemorrhage; $\mathrm{HI}=$ hemorrhagic infarction; NIHSS = National Institutes

of Health Stroke Scale; mRS = modified Rankin Scale; ASPECTS = Alberta Stroke

Program Early CT score

treatment. ${ }^{14,20-23}$ Although MR-based imaging has superior sensitivity and specificity compared to $\mathrm{CT}^{24}$, a CT and CTAbased approach may be enough. The lack of MR availability in majority of centers, the duration of imaging and feasibility concerns impair more widespread use of MR for stroke. ${ }^{22,23,25-29}$ Further, it is increasingly clear that there is a significant time trade off to intensive multimodal imaging. ${ }^{30}$

ASPECTS is an useful scoring tool to detect early ischemic changes on NCCT brain in patients with middle cerebral artery territory stroke because it is easy to access, learn and interpret. An ASPECTS of 4 or less corresponds well with the $1 / 3^{\text {rd }}$ MCA rule and ${ }^{31}$ at a threshold of ASPECTS $<8$, endovascular therapy is not likely to improve average outcomes. ${ }^{31,32}$ ASPECTS score is prognostically relevant but requires high quality, usually nonhelically acquired, imaging with careful review of the images. Further it is useful only in patients with stroke involving anterior circulation. ${ }^{12}$ Similarly CTA is prognostically relevant, helpful in planning endovascular therapy and confirms a logical target for thrombolytic therapy. It also requires high quality acquisition, careful timing of the intravenous contrast injection and may be limited to those patients without renal impairment. ${ }^{33,34}$ In the present study, the decision to treat these patients was primarily based on imaging findings with ASPECTS $>7$ together with a proximal vessel occlusion. We conclude that these patients can be safely treated with thrombolytic therapy but cannot assess efficacy in this single cohort design.

One-third of our patients had posterior circulation occlusions and anecdotally, it is believed that these patients have a longer relevant time window for thrombolysis. Although the usefulness of the good scan-occlusion model is not as applicable among patients with posterior circulation stroke due to inability to estimate early ischemic change well with CT alone, our results nevertheless confirm the safety of the CT-based approach in these patients.

Patient selection likely explains the lack of difference in outcomes. (Table 1) However, we also consider that patients in late or undefined time windows have a different natural history than those in the usual $4.5 \mathrm{hr}$ window. Indeed, in the ECASS2 and ECASS3 trials, patients had lower average severity of stroke measured on the NIHSS score compared to the NINDS tPA trial where patients were treated much earlier after stroke onset. ${ }^{14,20}$ Consequently, the placebo groups in both of the ECASS trials fared much better than in the NINDS tPA Stroke trial. Perhaps because of collateral circulation or differences in tissue susceptibility, these later time-window patients may do well without thrombolysis. Randomized data are needed to answer this question.

This is a retrospective study with inherent limitations of this study design. We did not assess patients with non-visualized occlusion such as small vessel ischemic disease. The numbers of patients is small in the reperfusion therapy arm and the results are not adjusted to show the effect of early recanalization and leptomeningeal collateral status, which are important parameters for tissue salvage. Outcomes were assessed in clinical routine and unblinded to patient treatment and patients who received recanalization therapies (IV+IV/IA+IA) were lumped into one group. We were unable to obtain glucose levels on all the patients and therefore did not assess this variable as a modifier of outcome; in prior studies it has been shown to be important. ${ }^{35}$ Thrombolytic and endovascular treatment in patients with stroke on awakening selected using a CT-based paradigm, are potentially safe using a good scan-occlusion paradigm and the hypothesis that thrombolytic therapy is helpful in these patients is worthwhile to test in a clinical trial.

\section{ACKNOWLEDGEMENTS ANd FUNDING}

MDH is funded by the Heart \& Stroke Foundation of Alberta, NWT, NU, and by Alberta Innovates Health Solutions.

AMD is funded by Alberta Innovates Health Solutions 


\section{Statement of Authorship}

SB wrote the primary draft of this manuscript. Data were analyzed and collected by SB, RB, NS and MDH. All authors provided editorial input on the final manuscript. MDH provided overall authorship and responsibility as the senior author.

\section{REFERENCES}

1. Kelly-Hayes M, Wolf PA, Kase CS, Brand FN, McGuirk JM, D'Agostino RB. Temporal patterns of stroke onset. The Framingham Study. Stroke. 1995;26(8):1343-7.

2. Lago A, Geffner D, Tembl J, Landete L, Valero C, Baquero M. Circadian variation in acute ischemic stroke: a hospital-based study. Stroke. 1998;29(9):1873-5.

3. Nadeau JO, Fang J, Kapral MK, Silver FL, Hill MD. Outcome after stroke upon awakening. Can J Neurol Sci. 2005;32(2):232-6.

4. Mackey J, Kleindorfer D, Sucharew H, et al. Population-based study of wake-up strokes. Neurology. 2011;76(19):1662-7.

5. Adams HP, Jr., Leira EC, Torner JC, et al. Treating patients with 'wake-up' stroke: the experience of the AbESTT-II trial. Stroke. 2008;39(12):3277-82.

6. Lansberg MG, Schrooten M, Bluhmki E, Thijs VN, Saver JL. Treatment time-specific number needed to treat estimates for tissue plasminogen activator therapy in acute stroke based on shifts over the entire range of the modified Rankin Scale. Stroke 2009;40(6):2079-84.

7. Lees KR, Bluhmki E, von Kummer R, et al. Time to treatment with intravenous alteplase and outcome in stroke: an updated pooled analysis of ECASS, ATLANTIS, NINDS, and EPITHET trials. Lancet. 2010;375(9727):1695-703.

8. Albers GW, Thijs VN, Wechsler L, et al. Magnetic resonance imaging profiles predict clinical response to early reperfusion: the diffusion and perfusion imaging evaluation for understanding stroke evolution (DEFUSE) study. Ann Neurol. 2006;60(5): 508-17.

9. Fink JN, Kumar S, Horkan C, et al. The stroke patient who woke up: clinical and radiological features, including diffusion and perfusion MRI. Stroke. 2002;33(4):988-93.

10. Hill MD, Kenney C, Dzialowski I, et al. Tissue Window in Stroke Thrombolysis study (TWIST): a safety study. Can J Neurol Sci. 2013;40(1):17-20.

11. Canadian Stroke Strategy Best Practices and Standards Writing Group. Canadian best practice recommendations for stroke care (update 2010). Ottawa (ON): Canadian Stroke Strategy; 2010. Available: http://www.strokebestpractices.ca

12. Hill MD, Demchuk AM, Tomsick TA, Palesch YY, Broderick JP. Using the baseline CT scan to select acute stroke patients for IVIA therapy. AJNR Am J Neuroradiol. 2006;27(8):1612-6.

13. Barber PA, Demchuk AM, Zhang J, Buchan AM. Validity and reliability of a quantitative computed tomography score in predicting outcome of hyperacute stroke before thrombolytic therapy. ASPECTS Study Group. Alberta Stroke Programme Early CT Score. Lancet. 2000;355(9216):1670-4.

14. Hacke W, Kaste M, Bluhmki E, et al. Thrombolysis with alteplase 3 to 4.5 hours after acute ischemic stroke. N Engl J Med. 2008; 359(13):1317-29.

15. Cho AH, Sohn SI, Han MK, et al. Safety and efficacy of MRI-based thrombolysis in unclear-onset stroke. A preliminary report. Cerebrovasc Dis. 2008;25(6):572-9.

16. Kang DW, Kwon JY, Kwon SU, et al. Wake-up or unclear-onset strokes: are they waking up to the world of thrombolysis therapy? Int J Stroke. 2012;7(4):311-20.

17. Natarajan SK, Snyder KV, Siddiqui AH, Ionita CC, Hopkins LN, Levy EI. Safety and effectiveness of endovascular therapy after 8 hours of acute ischemic stroke onset and wake-up strokes. Stroke. 2009;40(10):3269-74.
18. Barreto AD, Martin-Schild S, Hallevi H, et al. Thrombolytic therapy for patients who wake-up with stroke. Stroke; a journal of cerebral circulation. 2009;40(3):827-32.

19. Silva GS, Lima FO, Camargo EC, et al. Wake-up stroke: clinical and neuroimaging characteristics. Cerebrovasc Dis. 2010;29(4): 336-42.

20. Hacke W, Kaste M, Fieschi C, et al. Randomised double-blind placebo-controlled trial of thrombolytic therapy with intravenous alteplase in acute ischaemic stroke (ECASS II). Second European-Australasian Acute Stroke Study Investigators. Lancet. 1998;352(9136):1245-51.

21. Tissue plasminogen activator for acute ischemic stroke. The National Institute of Neurological Disorders and Stroke rt-PA Stroke Study Group. N Engl J Med. 1995;333(24):1581-7.

22. Furlan AJ, Eyding D, Albers GW, et al. Dose Escalation of Desmoteplase for Acute Ischemic Stroke (DEDAS): evidence of safety and efficacy 3 to 9 hours after stroke onset. Stroke. 2006; 37(5):1227-31.

23. Hacke W, Albers G, Al-Rawi Y, et al. The Desmoteplase in Acute Ischemic Stroke Trial (DIAS): a phase II MRI-based 9-hour window acute stroke thrombolysis trial with intravenous desmoteplase. Stroke. 2005;36(1):66-73.

24. Chalela JA, Kidwell CS, Nentwich LM, et al. Magnetic resonance imaging and computed tomography in emergency assessment of patients with suspected acute stroke: a prospective comparison. Lancet. 2007;369(9558):293-8.

25. Iosif C, Oppenheim C, Trystram D, Domigo V, Meder JF. MR imaging-based decision in thrombolytic therapy for stroke on awakening: report of 2 cases. AJNR Am J Neuroradiol. 2008;29 (7):1314-6.

26. Breuer L, Schellinger PD, Huttner HB, et al. Feasibility and safety of magnetic resonance imaging-based thrombolysis in patients with stroke on awakening: initial single-centre experience. Int $\mathbf{J}$ Stroke. 2010 Apr;5(2):68-73.

27. Kohrmann M, Juttler E, Fiebach JB, et al. MRI versus CT-based thrombolysis treatment within and beyond the $3 \mathrm{~h}$ time window after stroke onset: a cohort study. Lancet Neurol. 2006;5(8): 661-7.

28. Schellinger PD, Thomalla G, Fiehler J, et al. MRI-based and CTbased thrombolytic therapy in acute stroke within and beyond established time windows: an analysis of 1210 patients. Stroke. 2007;38(10):2640-5.

29. Fink JN, Kumar S, Horkan C, et al. The stroke patient who woke up: clinical and radiological features, including diffusion and perfusion MRI. Stroke. 2002;33(4):988-93.

30. Meretoja A, Strbian D, Mustanoja S, et al. Reducing in-hospital delay to 20 minutes in stroke thrombolysis. Neurology. 2012;79 (4):306-13.

31. Dzialowski I, Hill MD, Coutts SB, et al. Extent of early ischemic changes on computed tomography (CT) before thrombolysis: prognostic value of the Alberta Stroke Program Early CT Score in ECASS II. Stroke. 2006;37(4):973-8.

32. Hill MD, Rowley HA, Adler F, et al. Selection of acute ischemic stroke patients for intra-arterial thrombolysis with pro-urokinase by using ASPECTS. Stroke. 2003;34(8):1925-31.

33. Ledezma CJ, Wintermark M. Multimodal CT in stroke imaging: new concepts. Radiol Clin North Am. 2009;47(1):109-16.

34. Romero JM. CT angiography source image evaluation for stroke. Semin Ultrasound CT MR. 2005;26(6):387-93.

35. Poppe AY, Majumdar SR, Jeerakathil T, Ghali W, Buchan AM, Hill MD. Admission hyperglycemia predicts a worse outcome in stroke patients treated with intravenous thrombolysis. Diabetes Care. 2009;32(4):617-22. 